
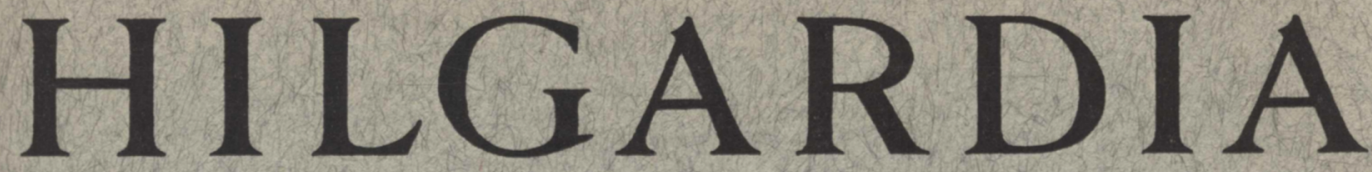

A Journal of Agricultural Science Publisbed by the California Agricultural Experiment Station

\title{
A SHORT METHOD OF DETERMINING LEAF AREA \\ AND VOLUME GROWTH IN PINE TREES
}

FREDERICK S. BAKER 


\section{CONTENTS}

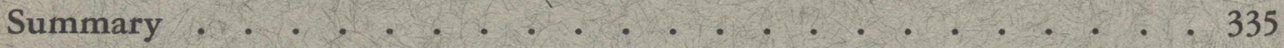

Introduction . . . . . . . . . . . . . . . . . . . . 335

Basic problem . . . . . . . . . . . . . . . . . 337

Present study . . . . . . . . . . . . . . . . . . . . 337

Leaf area, leaf volume, and branch increment . . . . . . . . . 338

Stratification of material . . . . . . . . . . . . . . . 339

First stratification-crown section . . . . . . . . . . . . 339

Second stratification-age of twigs . . . . . . . . . . . . 339

Third stratification-size . . . . . . . . . . . . . . . 340

Leafless branches - second stratification . . . . . . . . . 343

Determination of the average twig . . . . . . . . . . . 344

Random sampling . . . . . . . . . . . . . . . . . 344

Selection of the average twig . . . . . . . . . . . . . . . 344

Estimation of the number of leaves . . . . . . . . . . . 346

Estimation of wood increment in the test tree . . . . . . . . 346

Diameters of selected median twigs . . . . . . . . . . 349

Discussion . . . . . . . . . . . . . . . . . . . . 353

Literature cited . . . . . . . . . . . . . . . . 356 


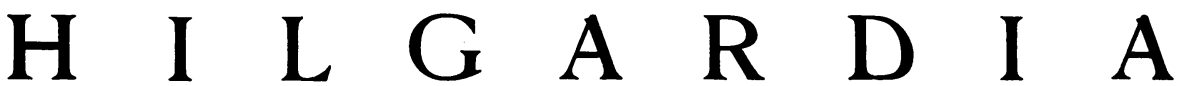

A Journal of Agricultural Science Published by

the California Agricultural Experiment Station

VoL. 18

August, 1948

No. 8

\section{A SHORT METHOD OF DETERMINING LEAF AREA AND VOLUME GROWTH IN PINE TREES}

\author{
FREDERICK S. BAKER
}

\section{SUMMARY}

The determination of leaf area, leaf increment, and wood increment, and their interrelations, give a valuable insight into the basic conditions of tree growth. The methods of analysis used to date have been so expensive in time and labor that investigations of this type have been discouraged.

The chosen median twig method is described as a means of determining leaf area, leaf volume, and wood increment of twigs at a reasonable expenditure of time and a satisfactory degree of accuracy. In this method, the needle-bearing twigs of the entire crown are removed and are stratified in the following three stages:

a. Upper crown, midcrown, and lower crown

b. Age (the twigs being cut at annual nodes)

c. Size

In each final stratified class an average twig is selected from a small group centering upon the median value of the class. It is shown that the twig so selected tends to be larger thàn average in linear dimensions, but that, since the desideratum is the twig of mean wood volume which varies with the square of the diameters, the errors come close to balancing and the chosen median twig is actually very nearly the twig of mean volume.

The leafless branches and the bole present less complex problems in sampling, and volume increment is determinable by standard methods without excessive labor.

\section{INTRODUCTION}

Many basic problems of forest growth could be approached advantageously through studies of leaf efficiency-determining the amount of solid substance produced annually per unit of photosynthetic area. Three major obstacles

${ }^{1}$ Received for publication July 18, 1947.

${ }^{2}$ Professor of Forestry and Silviculturist in the Experiment Station. 
block such studies: (1) the impossibility of measuring the entire annual increment, especially that in roots, bark, and fruits; (2) the impossibility of determining the true mean photosynthetic area, which varies throughout the growing season; and (3) the enormous amount of time and labor required to strip the needles from the tree and measure or weigh them, and to analyze the growth of the innumerable twigs.

The first two obstacles are not so serious as the third. European literature (Weber, $1925,{ }^{3}$ for example) indicates that about 80 per cent of the total weight increment of a forest tree is aboveground in the form of wood and leaves. Thus, a large proportion of total growth is readily available for measurement. The second difficulty is minor, as leaf area in evergreen trees past the juvenile stage does not vary greatly throughout the season. The third objection-that of expense and labor-seems to have rather effectively blocked study along these lines.

In spite of the laborious process, a few investigations of this type have been made. They have yielded interesting and significant evidence on a number of problems usually approached in other ways, often without particularly good success.

In Switzerland, the work of Bürger (1929, 1935, 1937, 1939, 1940, 1941, 1942 ) represents by far the largest contribution to the subject. It has shown that leaf efficiency of different species on the same site is surprisingly uniform, and that the common assumption that the increment of mixed stands is superior to the increment of pure stands is not substantiated. Bürger has also shown characteristic differences in the efficiency of trees of different crown classes, and has demonstrated the differences in the efficiency of tolerant and intolerant species. He has also shown that when spruce of different seed origins is planted in one place the stock of local seed origin usually gives the most efficient trees.

In this country, Hansen (1937) has analyzed, with interesting results, the increment per unit of leaf area of jack pine after thinnings. Kittredge (1944) has used the results of Bürger's, Hansen's and others' studies to find leaf area from increment and tree diameters. Other basic studies with less direct application to practice have been made by Dengler (1937), Burns and Irwin (1942), and MacDougal (1933, 1938). Very recently Möller (1945), in Denmark, has done interesting work of this type.

On the whole, the determination of the leaf efficiency of trees appears to be a valuable adjunct to other means of ecological study. It also tends to shed much light on the basic nature of forest and tree increment, particularly in its relation to age, crown classes, density of stands, and tolerance of shade. Such studies have not been made, however, largely because of the excessive amount of time required to analyze a whole tree to determine its leaf area and increment.

Although the authors cited have not generally described their methods of analysis too well, they appear usually to have undertaken the defoliation of the entire tree, after which they made a thorough analysis of growth. Bürger, however, determined increment by sampling methods. Simpler methods appear wholly feasible; one of these is described in this paper.

${ }^{3}$ See "Literature Cited" for citations, referred to in the text by author and date. 


\section{BASIC PROBLEM}

The ideal object in these studies is to determine dry weight-or volumeincrement of the entire tree per unit of leaf area, since leaf area appears to be the best measure of photosynthetic capacity (Uhl, 1937). As already noted, this ideal cannot be reached as the growth of bark and roots and the production of fruits are not determinable. Both the bole wood and the current crop of leaves can be readily determined, however. These make up some 80 per cent of the total weight of the tree.

The problem of determining the volume growth of the bole is standard in forest mensuration, and the best methods are well understood. They will be merely touched upon here. The branches and twigs are miniature boles, and their volume growth is determinable in precisely the same way. They introduce a new practical element, however, for they are very numerous and small, and require an inordinate amount of time for study. Much the same is true of the determination of needle volume and area. The computation is relatively simple, but to count the needles on a tree requires much time.

The problem of determining the photosynthetic area responsible for all this bole and branch growth is, in a sense, insoluble. Some of the growth came from stored foods, laid up the season before-the product, in part, of leaves which died, fell to the ground and became mixed with leaves of earlier years. In pine trees most of the growth is doubtless due to the persistent leaves already one to three years of age, but a portion of the late summer increment must be due to the leaves that have developed during the current season. The mean photosynthetic area responsible for the season's growth is therefore indeterminable. At the same time, leaf area does not vary greatly from year to year, as the new annual suites are only a little larger than the older suites that are discarded-except in young trees. The area from mid-July to midSeptember, when growth of the current year is complete and the abscission of the oldest suite has not yet begun, should give a fair index to average photosynthetic area. In young, rapidly growing trees this may not be true, as the net increase per season is very rapid. The problem then centers upon:

1. Determination of total leaf area as it appears in midsummer to late summer

2. The growth of the current year (taken during the period of dormancy, when the current season's growth is complete)

a. New suite of leaves (volume)

b. Wood volume

1) In bole

2) In branches and twigs

The determination of the leaf areas, the needle volume of the current year, and the growth of branchwood is the part of the work which has proved so time consuming and expensive in the past.

\section{PRESENT STUDY}

The present paper outlines a method whereby the work may be reduced to a reasonable level by means of stratification and sampling. On any large tree, there are obviously hundreds of twigs, closely similar in growth and foliage 
pattern. To measure each one involves a reduplication of work to no significant purpose.

The sampling method to be described was first tried out several years ago and proved to be simple and rapid. The work, however, was done in such a manner that neither statistical analysis nor even estimation of the probable errors could be made. Accordingly, a more careful study was made involving the detailed analysis of a single, small ponderosa pine tree.

This pine tree grew at an elevation of about 2,500 feet near Placerville, California. It was 28 feet tall and 6.9 inches in diameter on the stump, was 17 years old, and was codominant in crown class. To test personal bias, independent classifications and selection of samples were made by two workersthe writer and his daughter. Although one tree is a slender basis, the evidence all indicates that the errors of the method are relatively small. Under the circumstances, this presentation is made in the hope that it may encourage the forest ecologist to explore the use of a method which will not prove too cumbersome or too expensive of time, and which should furnish results sufficiently accurate to reveal the fundamentals of forest growth in an effective manner.

TABLE 1

Variation in Measures Related to Leaf Area and Wood INCREMENT IN TEST TREE

(Based on twigs of the current year only)

\begin{tabular}{|c|c|c|c|}
\hline & $\begin{array}{l}\text { Leaf fascicles } \\
\text { per twig }\end{array}$ & $\begin{array}{l}\text { Diameter twig } \\
\text { outside bark }\end{array}$ & $\begin{array}{l}\text { Wood volume } \\
\text { of twig }\end{array}$ \\
\hline Mean. & $\begin{array}{c}\text { number } \\
86.2\end{array}$ & $\begin{array}{l}m m \\
6.55\end{array}$ & $\begin{array}{r}c u c m \\
4.22\end{array}$ \\
\hline Maximum. & 405 & 17.5 & 80.9 \\
\hline Minimum. . & 12 & 2.2 & 0.1 \\
\hline Standard deviation................ & 65.8 & 2.28 & 10.0 \\
\hline
\end{tabular}

\section{Leaf Area, Leaf Volume, and Branch Increment}

It has already been pointed out that the leaf and twig measurements present the practical crux of the whole problem of determining leaf efficiency, and that the crown is made up of a great number of twig units, many of which are obviously similar. Any sampling technique must then be directed toward the accurate determination of the average twig which is, specifically, the one :

1. Bearing average leaf area (since leaves vary but little in size, this means practically average leaf numbers)

2. Bearing average leaf volume for the current year

3. Having average wood increment, which means virtually :

a. Average volume inside bark at end of current year

b. Average volume inside bark at beginning of the current year

The problem may be approached either through free random sampling of the entire mass of twig material or by stratification and more restricted sampling. Since economy is a primary objective of the method, it is evident at the outset that random sampling of all the twigs of a single tree is impossible, for variance is exceedingly large, skew is pronounced, and the different items 
whose mean is to be determined are not perfectly correlated. Table 1 gives data on a few typical measures to indicate the diversity of values that are encountered, while figure 2 shows the pronounced skew typical of the material. It is clear, without statistical analysis, that very heavy random sampling would be required to give a satisfactory estimate of the desired values.

Some degree of stratification is clearly needed to reduce variance, skew, and, if possible, to increase the degree of correlation between leaf area and wood increment in the sample.

\section{Stratification of Material}

The general plan of stratification has been : (1) to segregate the material from the upper, middle, and lower thirds of the tree crown; (2) to clip the leaf-bearing twigs at each annual node, to segregate the twigs of the current year, last year, the year before last, etcetera; and, in turn, (3) to sort these segregates into large, medium, and small classes. Figure 1 shows how this scheme worked out with the test tree.

First Stratification-Crown Section. The greatest single cause of wide variation in twig material and, in particular, the irregular and long-drawnout tail of the frequency histogram on the right (fig. 2) is the small number of very large and thrifty twigs in the upper crown of the tree. The crown may, therefore, first be divided into an upper third, marked by large twigs bearing many long thrifty needles, a middle third, of less strongly developed twigs, and a lower third, composed largely of suppressed twigs with fewer and somewhat shorter needles. For convenience in handling the material, the branches cut from the tree under study should be lopped off and gathered in three piles, one from each section of the crown.

Second Stratification-Age of Twigs. Since one of the objectives of the study is to determine leaf volume produced during the current year, as well as the current length growth of twigs, the twig growth of the current season must be segregated. This is easily recognized, and can readily be clipped off with pruning shears and placed in a separate pile. The older growth may be similarly separated into internodes of last year, the year before, and so on, to promote uniformity of material.

As will be shown later, the final sampling of twigs must be done by size. Growth of the last year varies with size of the twig only within a group of twigs of the same age, for the larger twigs have of course grown more rapidly. With twigs of various ages a large twig may be either very thrifty or very old-if the first, current wood increment will be large; if the second, it may be very small. Accordingly, it is desirable to cut the branches at the annual nodes back at least as far as the internodes bear needles. In the particular ponderosa pine studied, this was back three years. In other trees it has been observed that sometimes four suites are retained, at least in part. Farther back, where the internodes are barren of leaves, the nodal scars become less obvious, and the increasing stem diameter renders rapid clipping with pruning shears less feasible. Such leafless branch sections can hardly be stratified effectively in this manner; they will be omitted from immediate consideration.

Each of the segregates of leaf-bearing twigs represents fairly homogeneous material, although it still varies greatly in size, with a skewed distribution of 
values, as shown in the illustrative histogram for the miderown, last year's growth class, shown in figure 3.

Third Stratification-Size. The variation can be greatly reduced, and the skew largely eliminated by classifying each age class in each crown section by size. If controlled limits are contemplated, a series of fixed gauges could be constructed by which the stems could be rapidly calipered. In this study,

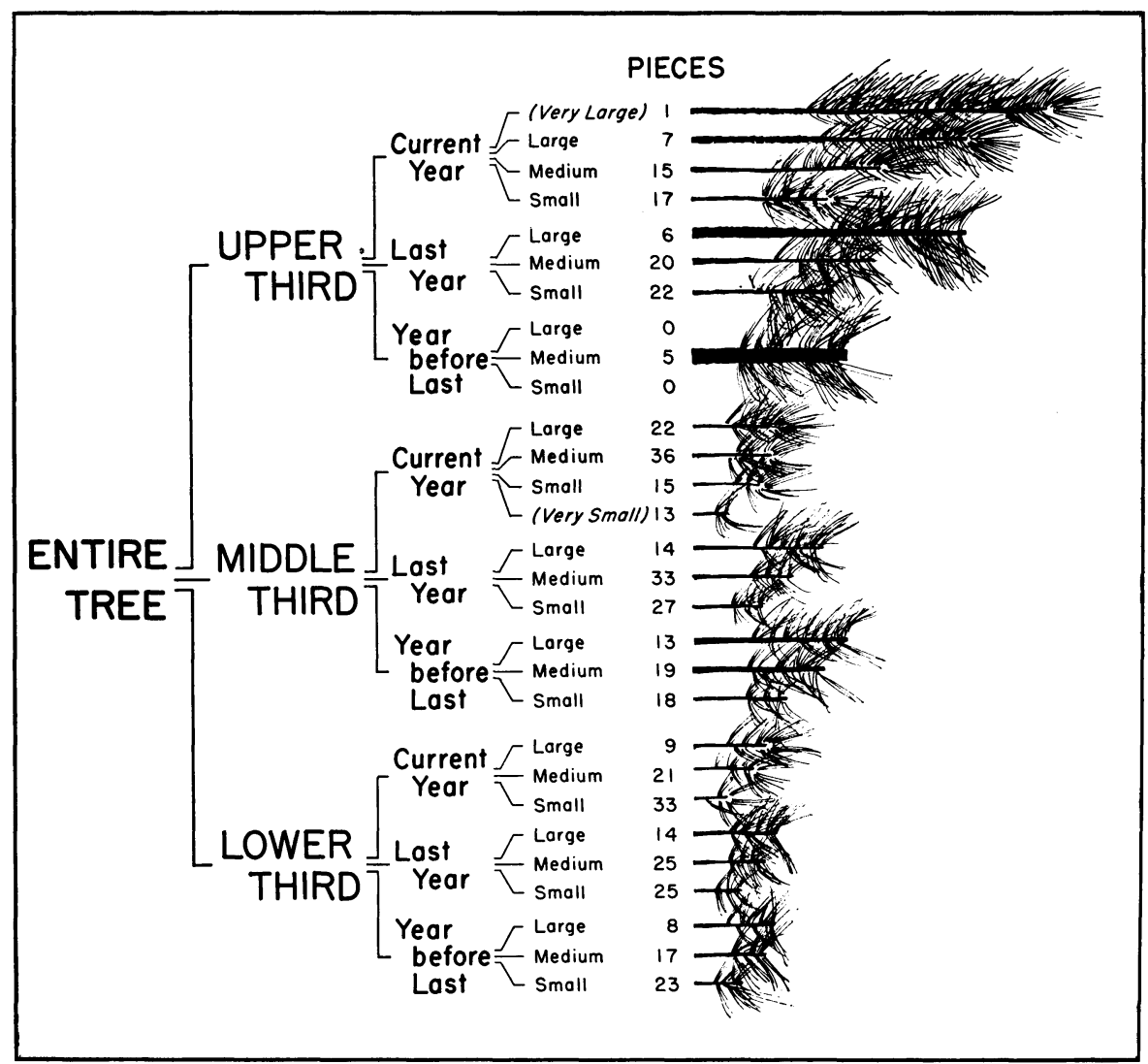

Fig. 1.-Diagram showing plan of stratification and its actual application in the test tree. Two extra categories are shown in italics. The twigs are drawn to scale as far as linear dimensions are concerned, but needles are merely suggestive.

however, economy was of great importance, and the segregation was made on the purely subjective basis of large, medium, small, with once a very large class and once a very small class.

In making the segregation, the analyst is obviously governed by many considerations-diameter, length, number of needles, and length of needles. Probably total weight would come as close to representing a concrete measure of size as anything. Weighing or any other actual measure of size slows down the analysis and offers few advantages. It is true that the size classes could be described and would have more sharply defined limits. However, since classification by diameter, for example, does not mean a clean-cut classification by 


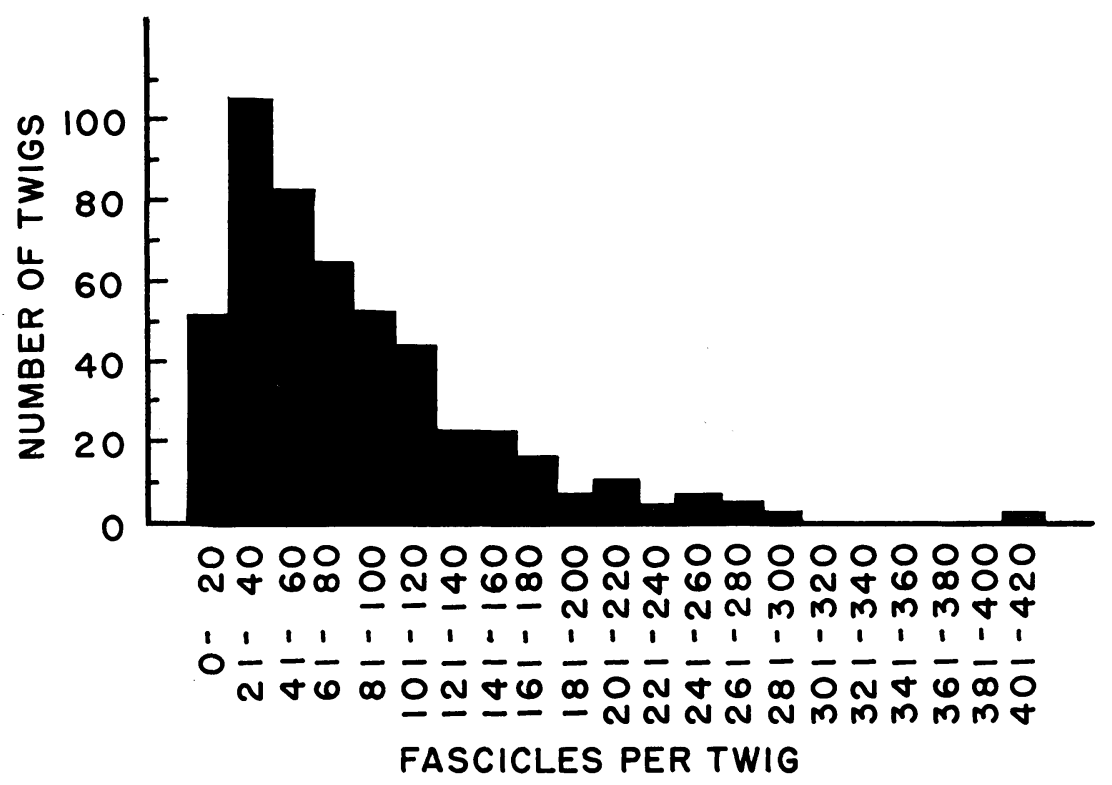

Fig. 2.- Histogram showing distribution of fascicles (leaves) per twig by 20 -fascicle frequency classes.

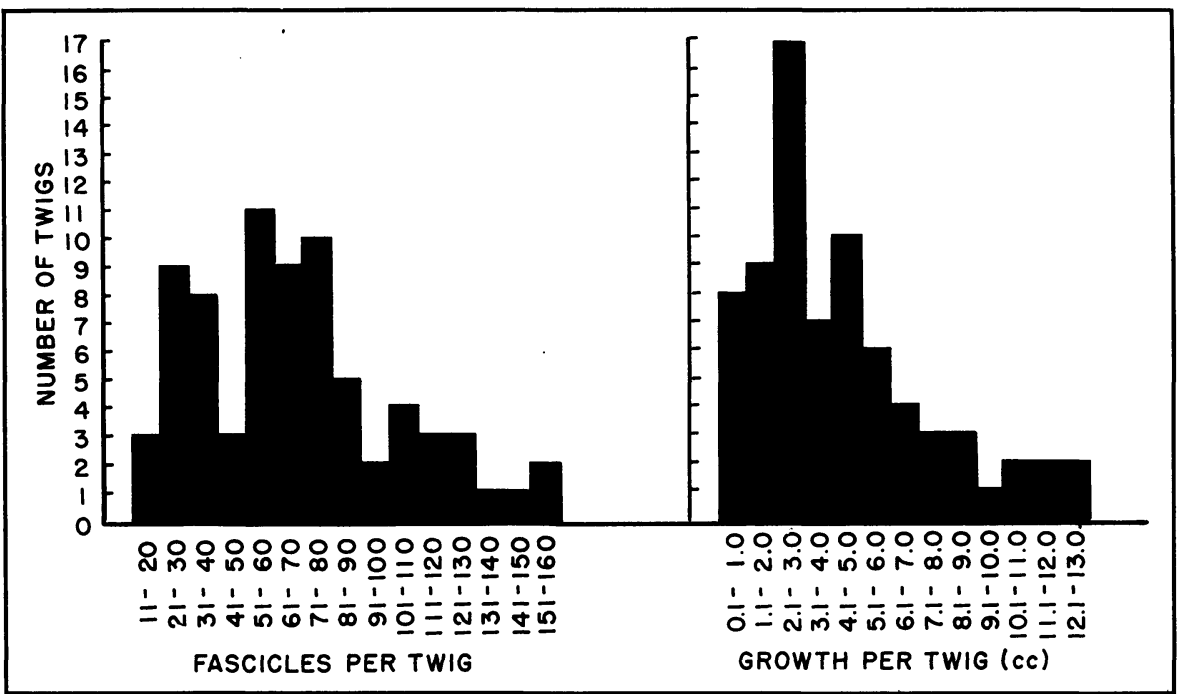

Fig. 3.- Histogram showing distribution of fascicles per twig by 10-fascicle classes and by volume per twig by 1 ce classes for the twigs of last year's growth in the miderown section. 
needle numbers, or by wood volume, or any other measure, and since none of these items is strictly correlated, little is gained thereby.

In the test tree of this study, several groups were stratified according to size by the two workers independently. The results are shown in table 2.

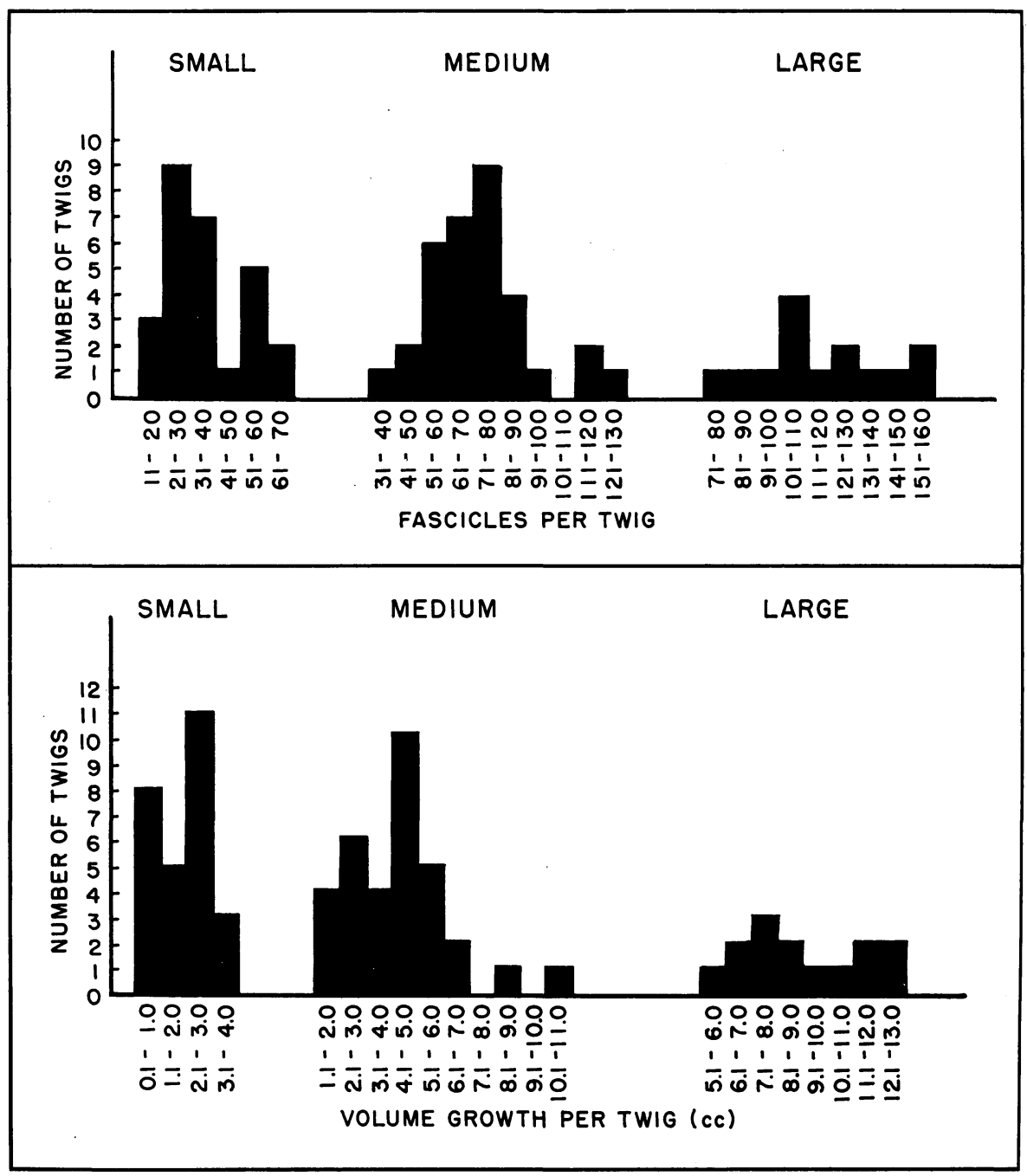

Fig. 4.-Histograms showing distribution of fascicles per twig and volume per twig resulting from the stratification of the "middle third of erown, last year's growth," into three classes based on size.

It is evident that, in the aggregate, no great differences exist between the size concepts of individuals. Even if there were considerable bias, it is doubtful whether accuracy would be reduced. The only conceivable bad effect might result from a large very-large class as against a small one. This class contains the greatest possible variance and needs to be small to promote homogeneity. 
The entire leaf-bearing portion of the twigs thus becomes segregated normally into 27 groups ( 3 crown levels $\times 3$ age classes $\times 3$ size classes). Each group is fairly uniform as to general character and pattern of growth, has small variance, and small skew. A typical situation is shown in the class entitled, "Middle

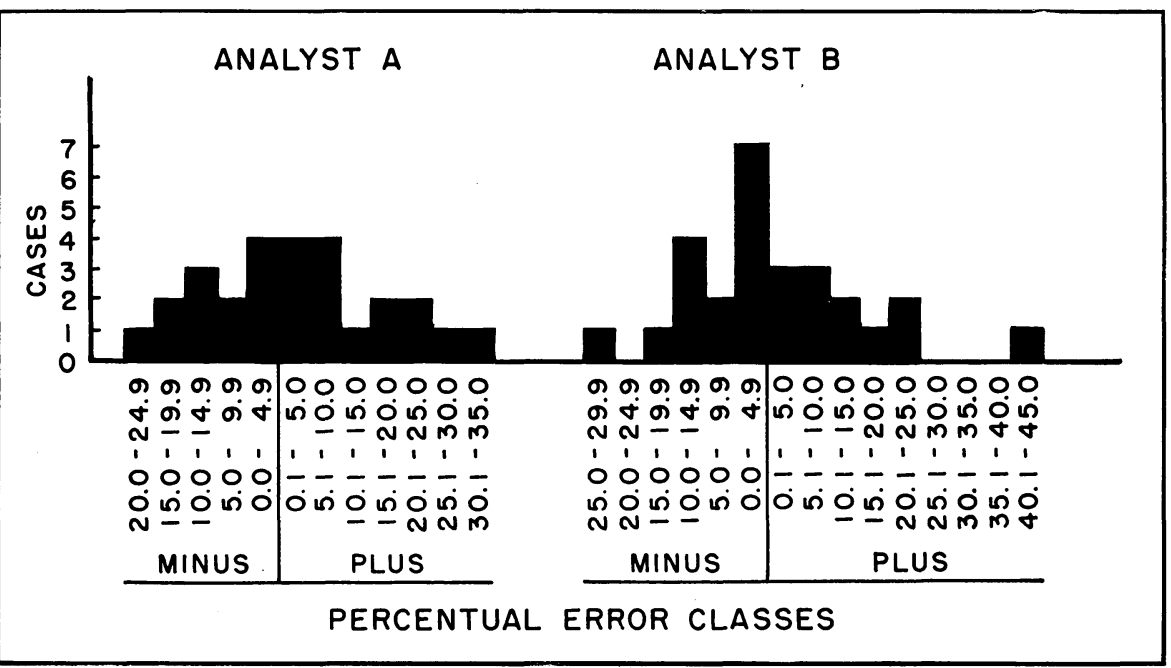

Fig. 5.-Histogram showing the distribution of percentual errors in the twig selected for average needle production by Analysts A and B.

third of crown, last year's growth" and its segregates into large, medium, and small classes (fig. 4).

Leafless Branches-Second Stratification. In the leafless branches and twigs, current wood volume increment is the single value to be secured. To

TABLE 2

Numbers of Twigs in Size Classes as Classed by Independent Analysts A and B

\begin{tabular}{|c|c|c|c|c|c|c|}
\hline & \multicolumn{2}{|c|}{ Large } & \multicolumn{2}{|c|}{ Medium } & \multicolumn{2}{|c|}{ Small } \\
\hline & A & B & A & $\mathrm{B}$ & A & B \\
\hline Lower third crown, last year's........... & 12 & 16 & 20 & 28 & 32 & 20 \\
\hline Lower third crown, this year's................ & 9 & 9 & 18 & 21 & 37 & 34 \\
\hline Middle third crown, this year's.............. & 22 & 19 & 41 & 35 & 11 & 20 \\
\hline Lower third crown, year before last.......... & 9 & 7 & 18 & 16 & 21 & 25 \\
\hline Total $\ldots \ldots \ldots \ldots \ldots \ldots \ldots \ldots \ldots \ldots \ldots \ldots \ldots$ & 52 & 51 & 97 & 100 & 101 & 99 \\
\hline
\end{tabular}

sample the branch wood effectively, then, it needs to be stratified in a manner that will bring variance in current wood volume increment to a low level. This increment depends upon three variables: (1) width of the last ring ; (2) circumferences of the last ring; and (3) length of the twig.

The branches should first be cut up to eliminate all forked pieces. By further calculated cutting, the branches can readily be reduced to one or, perhaps, a 
few groups, in each of which length variance is practically nil. The branches may then be segregated into three or, perhaps, more size groups-large, medium, and small-based on diameter at the midpoint. In such small trees analyzed to date by the author, the number of twigs in each of these categories has been very few. The average in each group has been selected by inspection of diameter and ring width, according to the general plan more elaborately applied to the leafy twig classes described later. As these leafless branches were not studied in the test tree, a more complete analysis can not be made of this class of twigs. Because the increment of the larger branches in the upper crown is considerable, the branches should be analyzed with a great deal of care.

\section{Determination of the Average Twig}

The next step is to sample each one of the segregated groups to determine, within satisfactory limits of accuracy, the twig of :

1. Mean current wood increment

2. Mean leaf area and, in twigs of current season's growth, the mean leaf volume

The approach may be either through random sampling or through a studied attempt to select the twig most nearly representative of the mean.

In either case, some standard of acceptable accuracy should be set up. Since the proportion of the wood increment of the entire tree which is laid down in these twigs is small—on the order of 1 per cent—no high degree of accuracy in wood increment determinations is called for. This is especially true of the smaller, suppressed twigs of the lower crown whose growth is so small as to be inconsequential. Under the circumstances, a standard error of the mean amounting to 10 per cent of the mean would appear amply accurate for the larger twigs in the upper crown where growth is concentrated. In the weakest twigs, 100 per cent errors would be permissible.

The determination of leaf areas and volumes requires greater accuracy, in a more uniform degree, in all parts of the crown. A standard error of no more than 10 per cent in any class would be desirable. This would result in a standard error of roughly $\sqrt{\frac{10}{27}}$ for the tree as a whole, or about 2 per cent.

Random Sampling. Accepting these levels of accuracy, the data presented in table 3 show that for a satisfactory determination of the mean needle number in each group-from which area and volume are readily computedthe random selection of about 7 twigs should be adequate. For the determination of volume increment, 15 twigs would be more nearly satisfactory-for the more important classes at least. These numbers are not large, considering the total number of twigs in each class with a tree of considerable size, yet for 27 classes they represent the analysis of several hundred twigs-no small amount of work. On this account, in spite of very real statistical advantages of random sampling, an attempt was made to select a single mean twig in each class by rather subjective means.

Selection of the Average Twig. The average twig in any class should be the twig of mean wood increment and of mean needle development. There is no assurance that the two are perfectly combined in the same twig although, 
as the coefficient of correlation is $0.888,{ }^{4}$ the chances are that there will be no wide discrepancy. ${ }^{5}$

The identification of the average twig is not simple. The current wood increment-the volume of the outermost ring-varies with the diameter of the twig, the thickness of the ring, and the length of the twig. It is impossible for the mind to size up subjectively the volume of such complex and "invisible"

TABLE 3

Number of Twigs, Sampled at Random, Required to Obtain Standard Error of 10 Per Cent of the Mean

\begin{tabular}{|c|c|c|c|c|c|c|}
\hline & \multicolumn{3}{|c|}{ Needles on twigs of } & \multicolumn{3}{|c|}{ Volume increment twigs of } \\
\hline & $\begin{array}{c}\text { Current } \\
\text { year }\end{array}$ & $\begin{array}{l}\text { Last } \\
\text { year }\end{array}$ & $\begin{array}{c}\text { Year } \\
\text { before last }\end{array}$ & $\begin{array}{c}\text { Current } \\
\text { year }\end{array}$ & $\begin{array}{l}\text { Last } \\
\text { year }\end{array}$ & $\begin{array}{c}\text { Year } \\
\text { before last }\end{array}$ \\
\hline \multicolumn{7}{|l|}{ Upper third crown } \\
\hline Large and very large. . & 7.1 & 2.6 & $\ldots$ & 18.2 & 7.7 & \\
\hline Medium ............. & 2.1 & 5.9 & 22.7 & 4.3 & 16.1 & 36.5 \\
\hline Small. . & 27.6 & 20.1 & $\ldots$ & 27.2 & 23.0 & $\ldots$ \\
\hline \multicolumn{7}{|l|}{ Middle third crown } \\
\hline Large.......... & 3.3 & 5.0 & 4.7 & 10.5 & 7.3 & 11.7 \\
\hline Medium. & 4.6 & 7.3 & 8.5 & 6.3 & 19.0 & 18.2 \\
\hline Small and very small. & 15.4 & 17.2 & 25.6 & 8.7 & 29.2 & 31.2 \\
\hline \multicolumn{7}{|l|}{ Lower third crown } \\
\hline Large........... & 7.0 & 5.8 & 7.7 & 11.0 & 14.7 & 10.7 \\
\hline Medium.... & 4.1 & 6.8 & 12.2 & 2.8 & 8.9 & 17.7 \\
\hline Small. . . . . . & 14.0 & 20.2 & 27.6 & 9.5 & 22.2 & 15.6 \\
\hline
\end{tabular}

solids. The leaf area problem is simpler. Needles vary little in length and diameter within a single twig size class. Needle number is the chief variable, and that can be judged fairly well.

The twig of average wood increment must therefore be chosen indirectly. The chief sensible item correlated with volume growth of wood is twig diameter (within a given age class), for large twigs of the same age will naturally tend to have greater annual increment than small twigs. This is not rigidly true, for the outermost ring may be abnormally large or small, and may be offset by abnormally small or large rings of earlier years. In general, however, twig growth is uniform and, accordingly, large twigs consistently mean large increment, as shown by the following correlation (coefficient of 0.242 is significant at the 1 per cent level) :

Diameter outside bark

and diameter inside bark. . . . . . . . 0.9517

and twig length .............. 0.9267

and diameter inside bark a year ago . . . . 0.9181

and wood increment (last ring) ....... 0.8875

The twigs in each group were therefore classed roughly by size, using again the rough general impression that is analogous to total weight.

In performing this classification, the twigs were spread out in a line, with

\footnotetext{
4 This was determined on the basis of top third, eurrent season's growth, and midthird, last year's growth only. The value appears to be characteristic, however.

${ }^{5}$ With 113 the degrees of freedom in this case, correlation is significant at the 1 per cent level when the coefficient is 0.242 .
} 
the smallest on the left and the largest on the right. Then, by counting off from one end, the median 5 twigs were taken out of the group and were carefully considered from a standpoint of characteristic foliage (length and number of needles), average bark (giving normal diameter inside bark), and ring width. Out of the 5 , the best single one was chosen.

With this purely subjective selection it becomes difficult to discuss the value of the chosen median twig, as representative of the average, in terms of statistical theory. There are too many complex interrelations. The best evidence of the feasibility of the method must come from the evidence of the test tree.

\section{Estimation of Number of Leaves}

The determination of the number of leaves on the test tree by the chosen median twig method used by the two analysts independently gave results that were slightly high in both cases. A's aggregate estimate was $1.9 \pm .1$ per cent high and B's was $1.3 \pm .1$ per cent. This aggregate error is fairly satisfactory, but a more careful analysis is needed to determine means of improving accuracy and to avoid gross errors. The details of the analysis are shown in table 4, an examination of which shows large percentual errors in line 5 (A), 11 (A and B), 12 (B), 17 (A and B), 20 (B), 27 (A).

A careful study of the field records disclose several causes of these large errors :

1. In small groups of twigs (line 5, 6 twigs, for example) no single twig closely resembles the mean.

2. It is difficult to find specific twigs that are median both in foliage (fascicle numbers) and in wood growth. This is the cause of most of the errors, as may be seen in table 5, where the twigs in groups with large leaf errors frequently have relatively small wood increment errors.

3. The preponderance of plus errors appears to be natural and unavoidable. If the average number of needles per twig is 30 , a twig with only 20 needles looks strikingly thin, but one with 40 does not look correspondingly overproductive of leaves.

\section{Estimation of Wood Increment in the Test Tree}

As already described, the selection of the twig of average increment for the current year was made in each of the 27 stratification groups by choosing the twig of average size and ring width. Diameter of outside bark and twig length are the major sensible dimensions upon which a choice of this kind is naturally founded. At the same time, the five semifinal median selections were also examined to determine whether bark and rings appeared to be of normal development. Small abnormalities are hardly discernible, being almost microscopic in twigs whose outside diameters are no more than 2 to 3 millimeters. Essentially then, the choice was made on the assumption that the twig of average diameter and length has average volume growth. This is, of course, flatly untrue.

In twigs of the current year's growth, which may be considered frustums of cones, volume may be expressed most readily by the formula known to foresters as "Huber's formula" :

$$
V=\pi R^{2} L
$$


where $V$ is the volume, $R$ the radius of the twig inside bark at a point halfway along the twig length, $L$. It is evident that in any group of twigs of varying size the twig of mean volume will have greater than mean diameter. This

TABLE 4

Errors in Determination of Leaf Numbers from Chosen Median Twigs

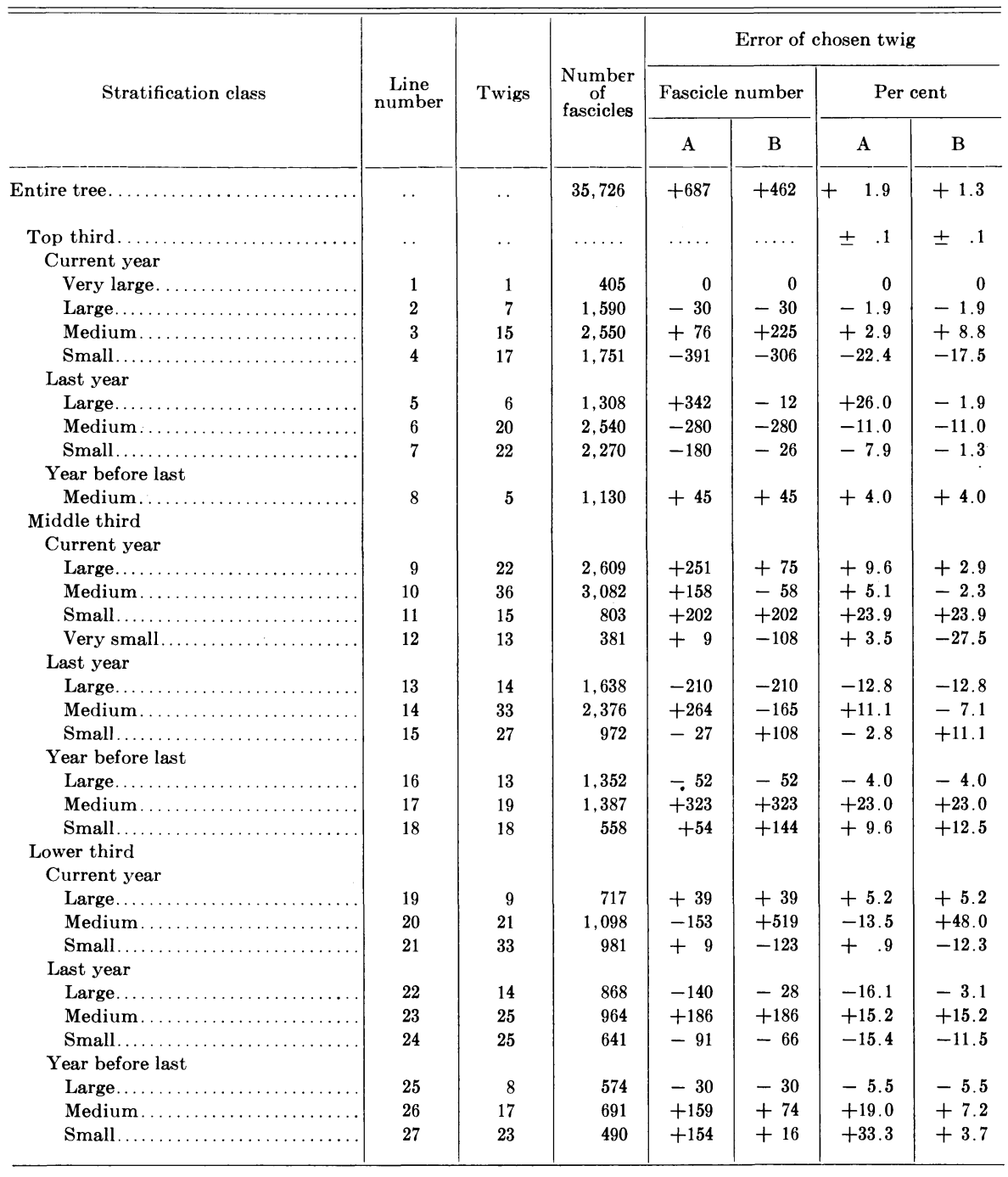

occurs because the squaring of the radius disproportionately enlarges the volume of the bigger twigs and correspondingly penalizes the smaller.

For example, in the class shown in line 7 , table 5 , the mean diameter outside bark is $9.51 \mathrm{~mm}$, inside bark is $6.33 \mathrm{~mm}$, and inside the last ring is 3.93 $\mathrm{mm}$. Twig length is $245 \mathrm{~mm}$. The volume outside bark of the twig of average diameter and length is $17.44 \mathrm{cc}$, but the average volume of the twigs in 
the class is $18.85 \mathrm{cc}$, a difference of $1.41 \mathrm{cc}$ (8.1 per cent). Similar differences exist in the volumes inside bark, at the present time and a year ago, so that the increment of the twig of average linear dimensions is $4.68 \mathrm{ec}$, although the mean volume increment is $5.27 \mathrm{cc}$. Thus, the twig of mean linear dimensions will have less than mean volume.

TABLE 5

ERrors of Wood InCREMENT Determination

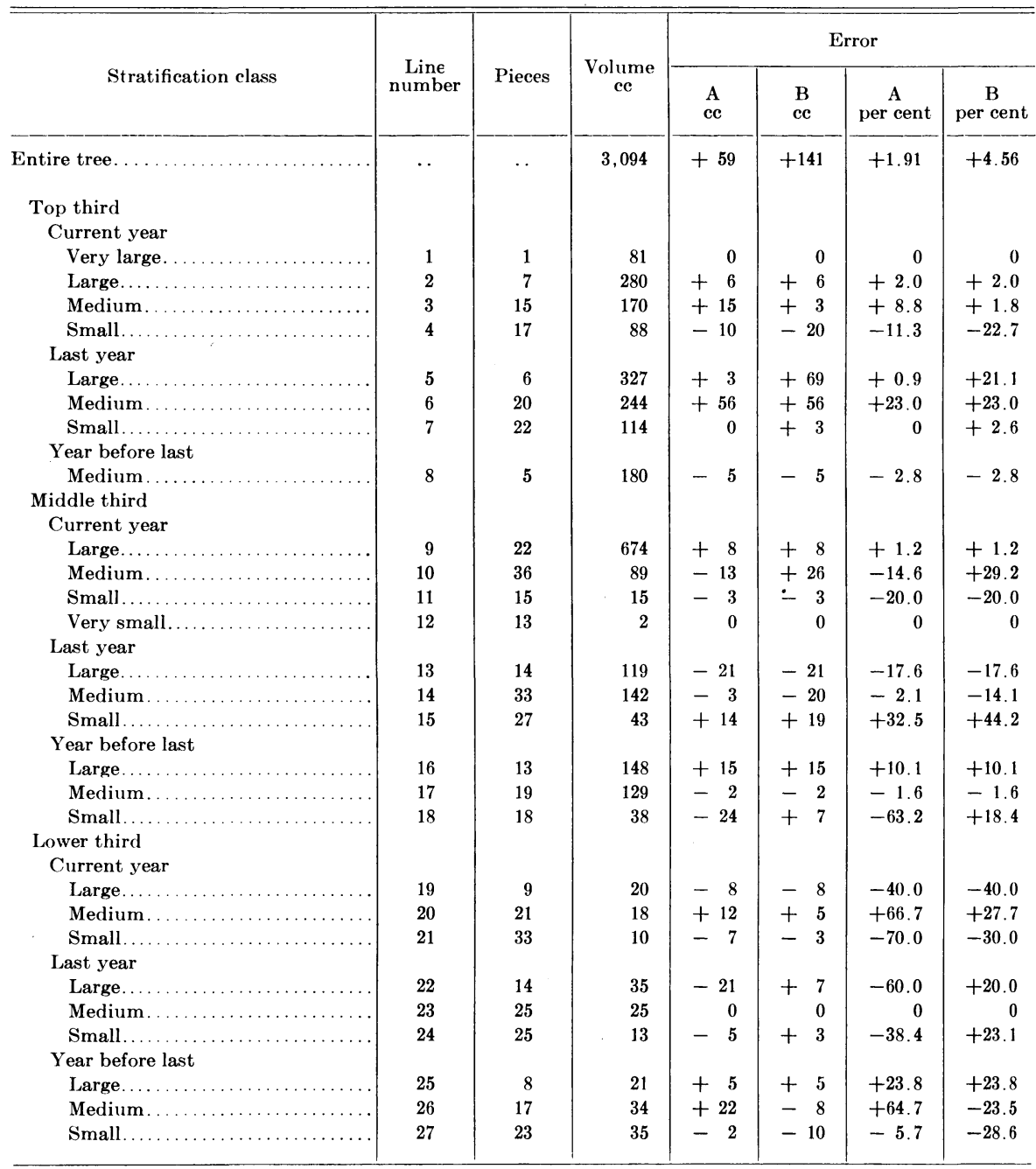

It becomes impossible to define the twig of mean volume growth in any practically satisfactory way, because mean volume growth may occur in a large twig with a small current ring or a small twig with a wide current ring. It is certain, however, that a twig of average diameter, average bark thickness, and average width of the current ring will have less than average volume. 
In this confusing situation, we may cut straight to the crux of the problem, and observe first of all how well the chosen twigs in the test tree represented the twig of mean volume increment in each of the 27 stratification classes.

As shown in table 5, the sampling was successful on the whole since, for the entire tree, A's error was about 2 per cent and B's, roughly $41 / 2$ per cent. A detailed examination of the table shows large and irregular percentual errors in the lower third of the tree and in the small categories in the middle third. These errors are not serious. They appear to be generally fortuitous and are largely compensating, and involve twigs which carry less than 1 per cent of the entire growth of the tree.

By far the most important errors are those made by both $A$ and $B$ on line 6 and B's large error on line 5. An examination of the original data shows that the first of these was occasioned by the selection of a mean sample twig which had a current ring $2.0 \mathrm{~mm}$ wide against an average of $1.5 \mathrm{~mm}$. In the second instance, the current ring was about $0.3 \mathrm{~mm}$ wider than the average of the group, and twig length was also somewhat excessive. It is hardly to be supposed that occasional errors of this magnitude can be avoided.

It will also be noted that $A$ had 5 errors in excess of 60 per cent. B's highest was 44 per cent. It happened that these large errors were chiefly compensating, but the effect is to give A a mean error of $21.8 \pm 6.1$ per cent and B one of $16.6 \pm 3.9$ per cent. ${ }^{\circ}$ This suggests a somewhat higher order of judgment by B than by A. An examination of the data, however, indicates that the more likely reason is that $A$ gave more weight to needle numbers in picking the median sample twig while B considered twig volume more carefully.

Examining the 25 cases in which errors of 10 per cent or greater exist, the most important reasons appear to be as follows :

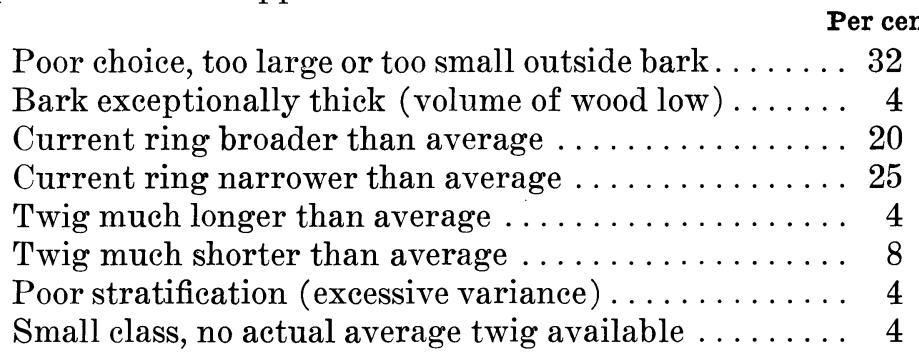

It is evident from this analysis that no one thing is strikingly at fault, but, in order to gain a more complete picture of the situation, a somewhat more detailed analysis is required.

Diameters of Selected Median Twigs. In order to study the characteristic errors in the diameter of the selected median twig, it is necessary to use the true mean diameter of the class from which the twig is selected as a fixed norm of comparison. But again it must be emphasized that this mean diameter is the diameter of a twig of less than mean volume. The discrepancy between the diameter of a twig of mean volume and that of mean diameter depends upon the degree of variance in the class. On the whole, however, in the material from

${ }^{8}$ These figures are the arithmetical means of the values in the last two columns disregarding algebraic sign, with corresponding standard deviation of the mean. 
the test tree, the twig of average volume has about $0.2 \mathrm{~mm}$ larger diameter than the twig of average diameter based on same twig length in both cases (table 6 ). The greatest differences between the two appear in the classes where

\section{TABLE 6}

Differences between the Twig of Mean Volume and the Twig of Mean Diameter with Respect to Diameter Inside Bark (D.I.B.) and Diameter Inside Bark a Year Ago (D.I.B.-1)*

(Computed on basis that both have same length)

\begin{tabular}{|c|c|c|}
\hline Stratification class & $\underset{\mathrm{mm}}{\text { D.I.B. }}$ & $\underset{\mathrm{mm}}{\text { D.I.B. }}$ \\
\hline \multicolumn{3}{|l|}{ Upper third } \\
\hline \multicolumn{3}{|l|}{ Current year } \\
\hline Very large..... & 0 & $\ldots$ \\
\hline Large.................. & .3 & $\ldots$ \\
\hline Medium ............... & 0 & $\ldots$ \\
\hline Small... & .2 & $\ldots$ \\
\hline \multicolumn{3}{|l|}{ Last year } \\
\hline Large. . & .2 & .2 \\
\hline Medium $\ldots \ldots \ldots \ldots \ldots \ldots \ldots \ldots \ldots \ldots \ldots \ldots \ldots$ & .4 & .3 \\
\hline$\ldots \ldots \ldots \ldots \ldots \ldots \ldots \ldots$ & .3 & .2 \\
\hline \multicolumn{3}{|l|}{ Year before last } \\
\hline Medium & .1 & .2 \\
\hline \multicolumn{3}{|l|}{ Middle third } \\
\hline \multicolumn{3}{|l|}{ Current year } \\
\hline$\ldots \ldots \ldots \ldots \ldots \ldots \ldots \ldots \ldots \ldots \ldots \ldots$ & 0 & $\ldots$ \\
\hline 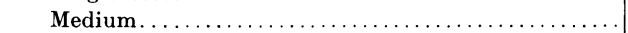 & .4 & $\ldots$ \\
\hline Small........... & .3 & $\ldots$ \\
\hline Very small.............................. & .1 & $\ldots$ \\
\hline \multicolumn{3}{|l|}{ Last year } \\
\hline Large.......... & .1 & .3 \\
\hline 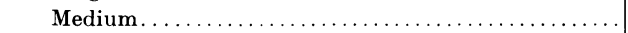 & .2 & .2 \\
\hline 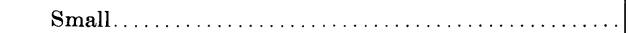 & .2 & .4 \\
\hline \multicolumn{3}{|l|}{ Year before last } \\
\hline Large......... & .4 & .3 \\
\hline 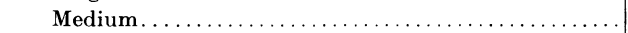 & .3 & .2 \\
\hline 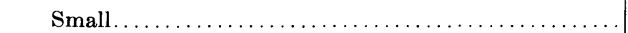 & .3 & .2 \\
\hline \multicolumn{3}{|l|}{ Lower third } \\
\hline \multicolumn{3}{|l|}{ Current year } \\
\hline 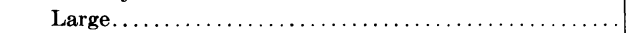 & .5 & $\ldots$ \\
\hline 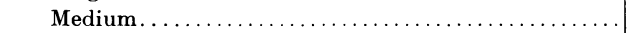 & .3 & $\ldots$ \\
\hline 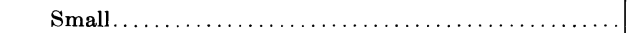 & 6 & $\ldots$ \\
\hline \multicolumn{3}{|l|}{ Last year } \\
\hline Large......... & .4 & .2 \\
\hline$\ldots \ldots \ldots \ldots \ldots \ldots \ldots \ldots \ldots \ldots \ldots$ & .3 & .5 \\
\hline (19.6. & .2 & .1 \\
\hline \multicolumn{3}{|l|}{ Year before last } \\
\hline Large.......... & .1 & .2 \\
\hline$\ldots \ldots \ldots \ldots \ldots \ldots \ldots \ldots \ldots \ldots \ldots$ & 0 & 0 \\
\hline$\ldots \ldots \ldots \ldots \ldots \ldots \ldots \ldots \ldots \ldots \ldots \ldots \ldots \ldots \ldots \ldots$ & .1 & 0 \\
\hline A verage. & .22 & .22 \\
\hline
\end{tabular}

* Twig of mean volume is always larger.

the twigs are very small and where variance-on a percentual basis-is correspondingly large.

Table 7 shows the accuracy with which the twig of mean diameter is selected by the analysts. There is a consistent tendency to pick twigs which are a little 
larger than the average. Since the actual visible evidence of diameter is that outside of bark, it is perhaps the most important diameter measure to inspect for bias and gross error.

\section{TABLE 7}

Errors in Diameter between the Chosen Mean Twig and the Twig of Average DiAmeter OUTSIdE BARK (D.O.B.), INSIDE BARK (D.I.B.) AND INSIDE BARK A YeAR Ago (D.I.B.-1)

\begin{tabular}{|c|c|c|c|c|c|c|c|}
\hline \multirow{3}{*}{ Stratification class } & \multirow{3}{*}{$\begin{array}{l}\text { Line } \\
\text { number }\end{array}$} & \multicolumn{6}{|c|}{$\begin{array}{l}\text { Diameter chosen twig minus average } \\
\text { diameter of class }(\mathrm{mm})\end{array}$} \\
\hline & & \multicolumn{2}{|c|}{ D.o.B. } & \multicolumn{2}{|c|}{ D.I.B. } & \multicolumn{2}{|c|}{ D.I.B. -1} \\
\hline & & $\mathrm{A}$ & $\mathrm{B}$ & A & B & A & B \\
\hline \multicolumn{8}{|l|}{ Upper third } \\
\hline \multicolumn{8}{|l|}{ Current year } \\
\hline Very large. & 1 & 0 & $\cdot 0$ & 0 & 0 & $\ldots$ & $\ldots$ \\
\hline Large.. & 2 & +1.0 & +1.0 & +.3 & +.3 & $\ldots$ & $\ldots$ \\
\hline Medium. & 3 & +.8 & -1.5 & +.2 & +.3 & $\ldots$ & $\ldots$ \\
\hline Small.... & 4 & +.3 & -1.8 & -.2 & -.5 & $\ldots$ & $\ldots$ \\
\hline \multicolumn{8}{|l|}{ Last year } \\
\hline Large... & 5 & +.3 & +.3 & +.5 & +.7 & +1.2 & +.2 \\
\hline Medium................ & 6 & +1.9 & +1.9 & +.7 & +.7 & -.3 & -.3 \\
\hline \multirow{2}{*}{\multicolumn{8}{|c|}{ Year before last }} \\
\hline & & & & & & & \\
\hline Medium....... & 8 & -.6 & -.6 & -.3 & -.3 & -.5 & -.5 \\
\hline \multicolumn{8}{|l|}{ Middle third } \\
\hline \multicolumn{8}{|l|}{ Current } \\
\hline Large... & 9 & +.1 & +.3 & +.1 & +.1 & $\ldots$ & $\ldots$ \\
\hline Medium. & 10 & +.3 & +.2 & +1.0 & 0 & $\ldots$ & $\ldots$ \\
\hline Small..... & 11 & +.1 & +.1 & +.2 & +.2 & $\ldots$ & $\ldots$ \\
\hline Very small. & 12 & +.2 & +.1 & +.1 & 0 & $\ldots$ & $\ldots$ \\
\hline \multicolumn{8}{|l|}{ Last year } \\
\hline Large... & 13 & -.2 & -.2 & -.3 & -.3 & -1.0 & -1.0 \\
\hline Medium.. & 14 & 0 & +.3 & +.1 & +.1 & +.4 & +.2 \\
\hline Small.......... & 15 & +1.4 & +.7 & +1.0 & +.4 & +.6 & -.1 \\
\hline \multicolumn{8}{|l|}{ Year before last } \\
\hline Large........... & 16 & +.7 & +.7 & +1.2 & +1.2 & +.8 & +.8 \\
\hline 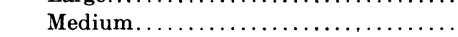 & 17 & -1.5 & -1.5 & -.3 & -.3 & -.9 & -.9 \\
\hline Small $\ldots \ldots \ldots \ldots \ldots \ldots \ldots \ldots \ldots \ldots \ldots \ldots$ & 18 & -1.5 & -.4 & -1.2 & +.1 & -1.1 & +.1 \\
\hline \multicolumn{8}{|l|}{ Lower third } \\
\hline \multicolumn{8}{|l|}{ Current } \\
\hline Large ............ & 19 & -.1 & -.1 & -.6 & -.6 & $\ldots$ & $\ldots$ \\
\hline Medium $\ldots \ldots \ldots \ldots \ldots \ldots \ldots \ldots \ldots$ & 20 & +.8 & +.2 & +.4 & +.5 & $\ldots$ & $\ldots$ \\
\hline Small......................... & 21 & +.2 & +.1 & 0 & -.2 & $\ldots$ & $\ldots$ \\
\hline \multicolumn{8}{|l|}{ Last year } \\
\hline Large.... & 22 & +.2 & +.4 & -.5 & +.5 & +.4 & -.1 \\
\hline Medium................ & 23 & +.3 & +.3 & +.3 & +.3 & +.8 & +.8 \\
\hline Small...................... & 24 & -.2 & +.5 & +.1 & +.4 & +.6 & -.4 \\
\hline \multicolumn{8}{|l|}{ Year before last } \\
\hline Large......... & 25 & +1.0 & +1.0 & +1.2 & +1.2 & +1.0 & +1.0 \\
\hline Medium.... & 26 & +.3 & -.4 & +.9 & +.2 & +.6 & +.6 \\
\hline 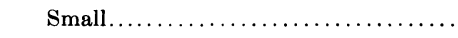 & 27 & +.2 & -.2 & & -.5 & -.1 & -.4 \\
\hline Average. . & $\ldots$ & +.22 & +.07 & +.17 & +.20 & +.07 & +.09 \\
\hline
\end{tabular}

In the 27 cases, A shows 18 plus errors, 3 zero errors, and 6 minus errors. B's errors are similarly divided -17 are plus, 1 is zero, and 9 are minus. The largest errors are in line number 6 , where large volume errors also occurred (table 4 ), the error being neary $2 \mathrm{~mm}$ (in a twig of $12 \mathrm{~mm}$ outside diameter). 
On the whole, it cannot be said that errors are either large or erratic. They do reflect, however, a definite tendency to select specimens somewhat larger than average.

TABLE 8

Errors in Length of Selected Twigs Compared with the Mean Length of Twig in Each Class

\begin{tabular}{|c|c|c|c|c|c|c|}
\hline \multirow{3}{*}{ Stratification class } & \multirow{3}{*}{$\begin{array}{c}\text { Line } \\
\text { number }\end{array}$} & \multirow{3}{*}{ Mean } & \multicolumn{4}{|c|}{ Error in length of twigs } \\
\hline & & & \multicolumn{2}{|c|}{ Number } & \multicolumn{2}{|c|}{ Per cent } \\
\hline & & & A & B & A & B \\
\hline \multicolumn{7}{|l|}{ Whole tree } \\
\hline \multicolumn{7}{|l|}{ Current year } \\
\hline Very large.. & 1 & 610 & 0 & 0 & 0 & 0 \\
\hline Large...... & 2 & 475 & +5 & +5 & +1.1 & +1.1 \\
\hline Medium... & 3 & 327 & +13 & -20 & +4.0 & -6.1 \\
\hline Small.... & 4 & 238 & +17 & +12 & +7.1 & +5.0 \\
\hline \multicolumn{7}{|l|}{ Last year } \\
\hline Large.. & 5 & 470 & +30 & +20 & +6.4 & +4.3 \\
\hline Medium. & 6 & 317 & -11 & -11 & -3.5 & -3.5 \\
\hline Small.... & 7 & 245 & +10 & +5 & +4.1 & +2.0 \\
\hline \multicolumn{7}{|l|}{ Year before last } \\
\hline Medium & 8 & 264 & -14 & -14 & -5.3 & -5.3 \\
\hline \multicolumn{7}{|l|}{ Middle third } \\
\hline \multicolumn{7}{|l|}{ Current year } \\
\hline Large...... & 9 & 148 & +2 & -3 & +1.3 & -2.0 \\
\hline Medium.... & 10 & 140 & 0 & 0 & 0 & 0 \\
\hline Small.... & 11 & 120 & -17 & -17 & -14.2 & -14.2 \\
\hline Very small. & - 12 & 65 & +5 & +20 & +7.7 & +30.8 \\
\hline \multicolumn{7}{|l|}{ Last year } \\
\hline Large. . & 13 & 229 & -59 & -59 & -25.8 & -25.8 \\
\hline Medium. & 14 & 178 & +22 & +22 & +12.3 & +12.3 \\
\hline Small... & 15 & 124 & -11 & +15 & -8.9 & +8.3 \\
\hline \multicolumn{7}{|l|}{ Year before last } \\
\hline Large. . . . . . & 16 & 263 & -23 & -23 & -8.7 & -8.7 \\
\hline Medium..... & 17 & 230 & -35 & -35 & -15.2 & -15.2 \\
\hline 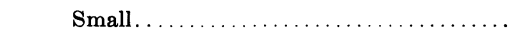 & 18 & 162 & -58 & +36 & -35.8 & +22.2 \\
\hline \multicolumn{7}{|l|}{ Lower third } \\
\hline \multicolumn{7}{|l|}{ Current year } \\
\hline Large...... & 19 & 122 & -7 & -7 & -5.7 & -5.7 \\
\hline Medium........ & 20 & 106 & +29 & +4 & +27.3 & +3.8 \\
\hline Small...... & 21 & 60 & -10 & +25 & -16.7 & +41.7 \\
\hline \multicolumn{7}{|l|}{ Last year } \\
\hline Large.... & 22 & 142 & -17 & +8 & -12.0 & +5.6 \\
\hline Medium. . & 23 & 127 & +37 & +37 & +29.0 & +29.0 \\
\hline Small......... & 24 & 81 & -11 & +9 & -13.6 & +11.1 \\
\hline \multicolumn{7}{|l|}{ Year before last } \\
\hline Large....... & 25 & 141 & -6 & +6 & -4.3 & -4.3 \\
\hline Medium....... & 26 & 123 & +42 & +12 & +34.2 & +9.8 \\
\hline Small............... & 27 & 85 & +18 & 0 & +21.2 & 0 \\
\hline Average. . & $\cdots$ & $\cdots$ & -1.8 & +1.3 & $\ldots$ & $\ldots$ \\
\hline
\end{tabular}

Diameters inside bark show a roughly similar trend. Both A and B have an average error of plus $0.2 \mathrm{~mm}$, but again the errors are neither very large nor erratic. Diameters inside bark of the test twigs a year ago average about 0.08 $\mathrm{mm}$ too large. 
We have already noted that the twig of mean volume in any segregated class has a diameter greater than the average of the class. A comparison of the data in tables 6 and 7 shows whether the selection of an inordinately large twig corrects or overcorrects this. As far as diameters inside bark are concerned, the average error indicates that the chosen median twig method almost precisely corrects the error. In the case of diameters a year ago, the error of only about $0.08 \mathrm{~mm}$, occasioned by picking a twig somewhat too large, is insufficient to correct the error of $0.22 \mathrm{~mm}$ in the opposite direction. The last ring is therefore computed a little too wide and volume is a little too high. These errors are small, however, and rest upon a dimension (diameter a year ago) which can be given little subjective weight in selection. The errors therefore seem of relatively minor statistical significance.

The distribution and nature of errors in the length of the median selected twig are shown in table 8. These errors are rather large percentually in the smaller twigs. For example, A's error of $42 \mathrm{~mm}$ in a class whose mean length is only $123 \mathrm{~mm}$ (line 26), errors of both A and B on line 23, A's error on line 18 , are all considerable on this basis. As pointed out before, the volume growth of these small weak twigs comprises a very minor part of the increment of the entire tree, and large errors are permissible. On the other hand, the errors in the large twigs are generally small-under 10 per cent.

It is possible that some of this error is deliberate- that is, the analyst selects a twig somewhat longer than average to compensate for an apparently small diameter. A check on this shows that in 34 cases (A and B) in which the chosen twig has a plus diameter error, the length errors are also plus in 21 cases. In the 15 cases where the diameter error is minus, the length error is also minus in 9 cases, showing no evidence of diametral errors offset by length errors. In fact, they tend to accentuate each other.

\section{DISCUSSION}

The evidence secured from the analysis of a single test tree indicates that the method used gives adequately accurate results with a minimum amount of labor. This method has here been called the chosen median method of sampling the stratified twig material composing the crown of a tree.

The determination of leaf area so far has been considered as though it was merely a determination of leaf numbers. Practically considered, this is true. In any group of twigs this is the big variable-length and cross section of needles are very uniform. Thus, in the chosen median twig, after the fascicles have been counted, determining the mean needle with high accuracy by any one of a number of methods is a simple matter.

Perhaps the most satisfactory means used by the writer was to select at random a sample of needles equal to about 10 per cent of the total. In these groups of from 2 to 40 needles (test tree) the fascicle of average length was selected by inspection. It was then sectioned in the middle with a razor blade, and the sections were mounted in water under a compound microscope with measuring eye piece. The length of one of the straight sides of the needle was then determined by averaging several of the sections. The perimeter of cross section, of the ponderosa pine needles, which are three to a fascicle, was computed on the basis that the cross section of each represents one third of a circle 
whose radius is the measured straight side of the needle. Needle nerimeter (P) in terms of the radius is therefore:

$$
\mathrm{P}=2 R+\frac{2 \pi R}{3} \text { or } 4.09 R
$$

and needle cross-sectional area $(\mathrm{A})$ is :

$$
\mathrm{A}=\frac{\pi R^{2}}{3} \text { or } 1.05 R^{2}
$$

Total area equals perimeter times length; volume equals cross-sectional area times length. Both formulas disregard taper of the needle which involves a small section toward the tip of the leaf. More complex formulas, taking this into consideration, may be derived without much difficulty if the additional accuracy appears warranted.

The determination of the wood increment of the leafy twigs, from the evidence of the test tree, can be determined with less than 5 per cent error. The chief causes of error to be guarded against are by far the most important in the large fast-growing branches of the upper crown. Here, where there is great variance and strong skew, careful stratification is required and the recognition of a "very large" class is usually advisable. The development of homogeneous classes is usually perfectly feasible by the use of good judgment. Single unconformable twigs may advantageously be handled singly.

The experience with the test tree suggests several other minor modifications to increase accuracy. Stratification classes in which the number of twigs is very small may lead to large errors. This can happen because no single twig appears to be average, particularly when both average leaf numbers and average wood increment are sought in combination. Four remedies are suggested :

1. Instead of trying to select an unsatisfactory median twig, record the class in toto without recourse to sampling.

2. Select one twig of average foliage development and another of apparently average wood increment.

3. Combine with another class to make larger numbers from which selection may be made.

4. Stratify the class still further.

The first alternative is absolutely safe, but requires more work. The second is probably both safe and economical, although it lacks any field test as yet. The third appears dangerous as it increases variance. The fourth may be quite feasible.

Even in the classes with larger numbers of twigs, the endeavor to select a twig that will be average in respect to both leaves and wood increment seems frequently to have been a cause of considerable error. It would probably increase accuracy, without increasing the work involved, if two median twigs were selected-one for average leaf numbers, the other for average development of wood. It is not impossible that the same twig might satisfy both requirements, but this does not appear to happen many times.

The problem of leafless branches was not studied in the test tree. In small trees, they may be handled individually as there are not many of them. In 
larger trees, they may be stratified as suggested, and sampled by the selected median twig method as in leafy twigs, with one precaution. This material is of varying ages-it has not been stratified by age as have leafy twigs. The selected median twig should therefore be carefully considered from the standpoint of diameter and width of the last ring, especially width of the last ring. Errors in the branch-wood increment are not of paramount importance when the tree increment is concerned, for branch growth comprises only about 20 per cent of the total. In computing wood increment, therefore, the greatest care must be exercised in the analysis of the bole.

It should be marked off into short "logs" from 50 to $100 \mathrm{~cm}$ long so arranged that knots, swellings, and injuries at the middle point of the log may be avoided. If this is done, normal diameters and ring widths may be secured. The volume is most easily computed by the Huber formula by which log volume is considered equal to the product of the cross-sectional area of the log at its midlength times its length. The logs should be sawed at their midpoint by cuts perpendicular to the axis of the bole, and great care should be taken to measure the true average diameter this year and a year ago, as great volume errors may be introduced by small errors in diameter measurements in the butt logs.

The method outlined has been applied only to trees less than 30 feet in height and 9 inches in diameter. In them, the amount of labor per tree is not excessive. As the trees grow larger, there are no greater numbers of segregated stratification groups (normally 27), but the number of twigs in each group increases and the labor of clipping and of counting, stratification, and determination of the chosen median twig increases considerably.

It is suggested that in large trees, with regularly developed crowns and whorls of branches, a single average branch may be cut at each node, instead of the whole whorl (normally 5 branches in pines). This would reduce the labor of clipping and segregation by four fifths, probably without any dangerous loss of accuracy. No test of this method has yet been made; it is merely a suggestion. 


\section{LITERATURE CITED}

BÜRGER, H.

1929. Holz, Blattmenge und Zuwachs. I Mitteilung. Die Weymouthsföhre. Schweiz. Centralanst. f. Forstl. Versuchsw. Mitt. 15(2):243-92.

1935. Holz, Blattmenge und Zuwachs. II Mitteilung. Die Douglasie. Schweiz. Centralanst. f. Forstl. Versuchsw. Mitt. 19(1):21-72.

1937. Holz, Blattmenge und Zuwachs. III Mitteilung. Nadelmenge und Zuwachs bei Föhren und Fichten rerschiedener Herkunft. Schweiz. Centralanst. f. Forstl. Versuchsw. Mitt. 20 (1):112-41.

1939. Baumkrone und Zuwachs in Zweihiebsreifen Fichtenbestanden. Schweiz. Centralanst. f. Forstl. Versuchsw. Mitt. 21(1) :147-76.

1940. Holz, Blattmenge und Zuwachs. IV Mitteilung. Ein 80 jahriger Buchenstand. Schweiz. Centralanst. f. Forstl. Versuchsw. Mitt. 21(2):307-48.

1941. Holz, Blattmenge und Zuwachs. V Mitteilung. Fichten und Föhren rerschiedener Herkunft auf rerschiedenen Kulturorten. Schweiz. Centralanst. f. Forstl. Versuchsw. Mitt. 22(1):10-62.

1942. Holz, Blattmenge und Zuwachs. VI Mitteilung. Ein Plenterwald mittlerer standortsgüte. Schweiz. Centralanst. f. Forstl. Versuchsw. Mitt. 22(2):377-445.

Burns, G. P. and E. S. Irwin.

1942. Studies in the tolerance of New England forest trees. XIV. Effect of spacing on efficiency of white and red pine needles as measured by the amount of wood production on the main stem. Vermont Agr. Exp. Sta. Tech. Bul. 499.

Dengler, A.

1937. Kronergrasse, Nadelmange und Zuwachsleistung von Altkiefern. Ztschr. f. Forstl. u. Jagdw. $69(7): 321-36$.

HANSEN, T. S.

1937. Ecological changes due to thinning jack pine. Minnesota Agr. Exp. Sta: Tech. Bul. 124.

KITTREDGE, J.

1944. Estimation of the amount of foliage of trees and stands. Jour. Forestry 42(12): 905-12.

MacdougaL, D. T.

1933. The relation of leaf-surface to wood formation in pine trees. Amer. Phil. Soc. Proc. $72: 325-32$.

1938. Tree growth. 240 p. Chronica Botanica Co., Leiden, Holland.

MöLLER, C. M.

1945. Untersuchungen über Laugmenge, Stoffverlust und Stoffproduktion des Waldes.

UHL, A. Copenhagen. Kandrup and Wunsch. (Doctor's thesis.)

1937. Untersuchungen über die Assimilations-verhältnisse und die Ursachen ihrer UnterWEBER, $\mathrm{H}$. schiede in der Gattung Pinus. Jahrb. f. Wiss. Bot. 85(3) :368-421.

1925. Die Bedentung des Waldes und die Aufgaben der Forstwirtschaft. In: Lorey, T. (ed.) Handbuch der Forstwissenschaft. vol. 1, p. 43-187. 
The journal Hilgardia is published at irregular intervals, in volumes of about 600 pages. The number of issues per volume varies.

Subscriptions are not sold. The periodical is sent as published only to libraries or to institutions in foreign countries having publications to offer in exchange.

You may obtain a single copy of any issue free, as long as the supply lasts; please request by volume and issue number from:

\section{Publications Office \\ College of Agriculture \\ Berkeley 4, California}

The limit to nonresidents of California is 10 separate issues on a single order. A list of the issues still available will be sent on request. 


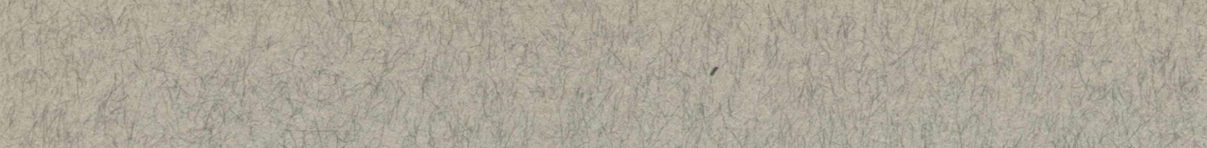

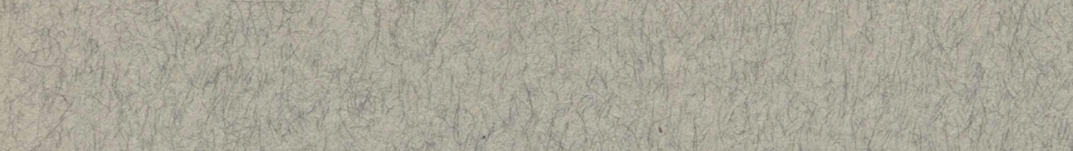

$$
\begin{aligned}
& \text { P. } \\
& \text { a. }
\end{aligned}
$$

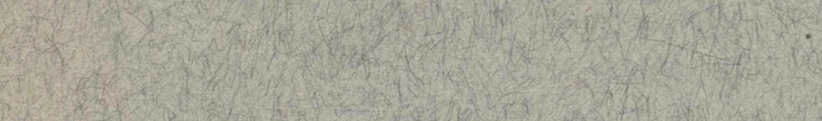

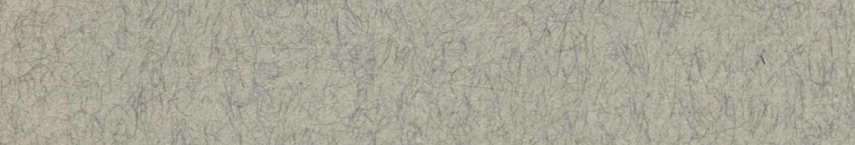

(2)

(1) (2)

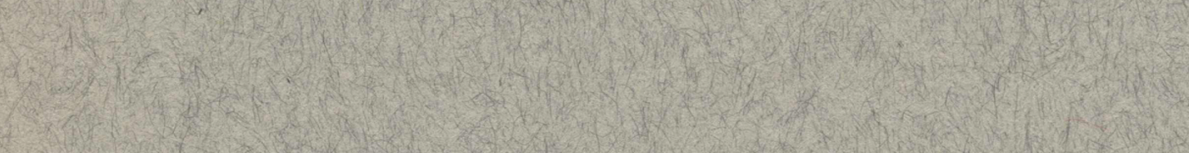

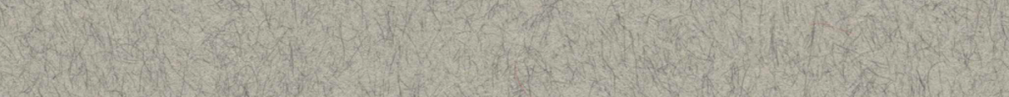
(2x) 12.0.

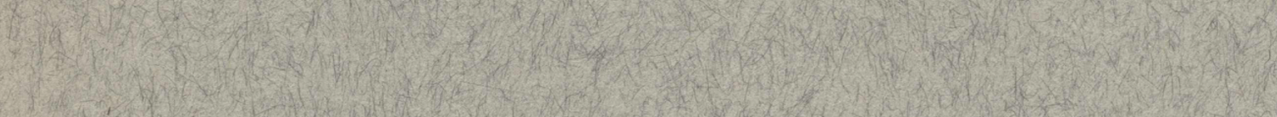

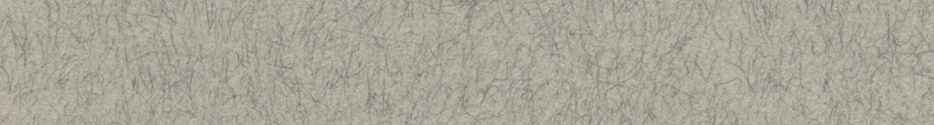

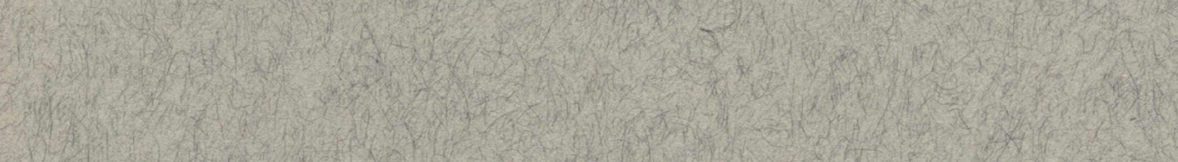

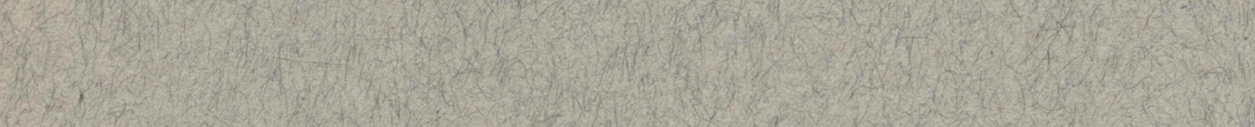

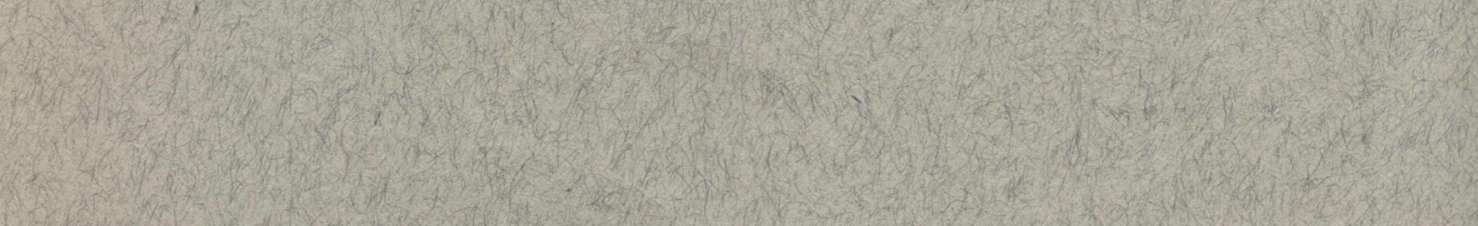

